\title{
Mammalian species richness on islands on the Sunda Shelf, Southeast Asia
}

\author{
Lawrence R. Heaney \\ Museum of Zoology and Division of Biological Sciences, University of Michigan, Ann Arbor, MI 48109, USA
}

\begin{abstract}
Summary. A rich mammalian fauna is found on islands that lie on the Sunda Shelf, a continental shelf extending from Vietnam to Borneo and Java that was periodically exposed as dry land during the Pleistocene. The correlation between $\log$ of island area and number of species is high $\left(r^{2}=0.94\right)$; the slope of the curve is moderate $(z=0.235)$. Distance from small islands to "source areas" (=Borneo, Sumatra, and the Malay Peninsula) does not appear to affect species richness, nor does depth of water to source area (a measure of isolation time). A species-area curve for forest reserves of varying sizes on the Malay Peninsula has a low slope $(z=0.104)$; comparison of the mainlaind and island curves indicates that decreasing island area is strongly correlated with increased extinction. Extinction has left reduced but ecologically balanced sets of species on all islands, except that carnivores are under-represented on all but the largest islands. Initial body size and rarity appear to play a significant role in determining the probability of extinction of individual species.
\end{abstract}

\section{Introduction}

The mammalian fauna of Southeast Asia represents an excellent subject for investigating the interrelationships of species richness, island area, and isolation. A large number of the islands that lie south of Indochina, including all those under study here, are merely highpoints on an immense shallow continental shelf known as the Sunda Shelf. This shelf was exposed periodically as dry land during glacial periods of the Pleistocene and was flooded during interglacials by rising sea levels (Dunn and Dunn 1977; Heaney 1978). Current islands range in size from some of the largest in the world to small atolls, and time since isolation, which can be estimated from the depth of surrounding water, varies markedly.

Wilcox (1980) recently used the insular mammalian fauna of the Sunda Shelf region as an example of "faunal collapse" following isolation of land bridge islands. In his discussion, he provided an estimate of the species-area relationship for non-volant land mammals on islands of the Sunda Shelf, and on the Malay Peninsula. As discussed below, some of the islands he included probably were not connected to the Sunda Shelf during the late Pleistocene, and others are in tectonically active areas, and so do not form an historically or geologically homogeneous group. Further, although Wilcox estimated area-dependent postPleistocene extinction of mammals, he did not investigate the chronology of extinction, and his analysis implicitly assumed (but did not test) that post-Pleistocene colonization has not taken place.
The purposes of this paper are to describe the terrestrial mammal fauna of the continental shelf islands of Southeast Asia, and to investigate the composition of insular faunas that have been depleted by decreasing island area. Additionally, some limitations of the equilibrium model of island biogeography are discussed. This paper deals only with non-volant land mammals because the distributions of bats and marine species on and near the small islands of Southeast Asia are poorly known.

\section{Methods}

The islands of Southeast Asia have been the subjects of studies of widely varying intensities. I have included in this investigation only the eleven most intensively collected small islands, most of which were sampled by W.L. Abbott and his large (5-15) crew of experienced collectors between 1897 and 1909 (Table 1). The locations of most of these were mapped by Heaney (1978). The largest islands (Borneo, Java, and Sumatra) have not had equivalent collecting effort, with Sumatra the least studied; undoubtedly a small percentage of species remains to be discovered, but this would not substantially affect a statistical treatment of such a rich fauna. Specific sources for the data are cited in the text and Table 1, except that lists of murid species on the large islands were taken from Musser (1981). The four largest land masses (including the Malay Peninsula) are here considered to be potential source-areas for immigrants to smaller islands; all distances given are minimum straightline distances. The Malay Peninsula is not used in calculating the island area-species richness curve because of its continuous post-Pleistocene connection to the Asian mainland.

All of the islands used in this study lie in water less than $85 \mathrm{~m}$ deep, and were almost certainly part of the Sunda Shelf "mainland" during the late Pleistocene, and periodically during earlier portions of the Pleistocene (Dunn and Dunn 1977; Wilks 1979). Moreover, all but one of the smaller islands lie in the tectonically stable central portion of the Sunda Shelf, rather than on the less stable margins of the shelf (see Hamilton 1979:102-113, and Pl. 1). Time of isolation for any given island is determined by the depth of its surrounding water, if it is in a tectonically stable area. Actual date of isolation could be estimated from data summarized by Bartlett and Barghoorn (1973), but I use depth of water here because it involves one less level of approximation, and is no less informative.

Four of the islands included by Wilcox (1980) in his analysis of Sunda Shelf mammals (Siberut, South Pagi, North Pagi, and Sipora) are in the Mentawi archipelago, which is separated from Sumatra by about $160 \mathrm{~m}$ of water, and so probably were not connected to the Sunda Shelf 
Table 1. Data used in analyses of species richness of mammals on Southeast Asian islands

\begin{tabular}{|c|c|c|c|c|c|c|}
\hline $\begin{array}{l}\text { Island } \\
\text { name }\end{array}$ & $\begin{array}{l}\text { Area } \\
\left(\mathrm{km}^{2}\right)\end{array}$ & $\begin{array}{l}\text { Elevation } \\
(\mathrm{m})\end{array}$ & $\begin{array}{l}\text { Distance } \\
\text { to source } \\
\text { area }(\mathrm{km})\end{array}$ & $\begin{array}{l}\text { Depth to } \\
\text { source } \\
\text { area }(\mathrm{m})\end{array}$ & $\begin{array}{l}\text { Number of } \\
\text { terrestrial } \\
\text { mammal } \\
\text { species }\end{array}$ & Source \\
\hline 1. Borneo & 743,244 & 4,101 & 0 & 0 & 129 & Medway (1977) \\
\hline 2. Sumatra & 473,607 & 3,805 & 0 & 0 & 126 & Chasen (1940) \\
\hline 3. Java & 125,628 & 3,428 & 0 & 0 & 78 & Chasen (1940) \\
\hline 6. Banggi & 450 & 572 & 12 & 29 & 18 & Medway (1977) \\
\hline 7. Jemaja & 194 & 495 & 202 & 59 & 15 & Chasen and Kloss (1927) \\
\hline 8. Karimata Besar & 130 & 1,030 & 65 & 20 & 19 & Medway (1977) \\
\hline 9. Tioman & 114 & 1,100 & 38 & 31 & 23 & Medway (1966) \\
\hline 10. Siantan & 113 & 600 & 265 & 59 & 16 & Chasen and Kloss (1927) \\
\hline 11. Sirhassan & 46 & 441 & 66 & 44 & 16 & Chasen (1935) \\
\hline 16. Selangor (forest reserve) & 389 & - & - & - & 76 & Harrison (1965) \\
\hline 17. Pahang (Krau Game Reserve) & 1.9 & 45 & - & - & 46 & Medway and Wells (1971) \\
\hline 18. Selangor (forest reserve) & 0.12 & - & - & - & 32 & Harrison (1965) \\
\hline
\end{tabular}

during the late Pleistocene. Tanabala, Tanamasa, Pini, Tuangku, and Bangkaru lie off the west coast of Sumatra, an area of great tectonic activity (Hamilton 1979), so they were not used in this study. Finally, I suspect that three islands used by Wilcox (Bali, Penang, and Singapore) were heavily disturbed before sampling took place, and so I do not include them.

Island areas, maximum elevations, and minimum distance to source areas were obtained from Operational Navigation Charts published by the Defense Mapping Agency Aerospace Center, St. Louis Air Force Station, Missouri. Areas were estimated by placing a sheet of transparent, gridded $(2.5 \times 2.5 \mathrm{~mm})$ plastic over the map and counting the number of grid squares covering an island. Depths were estimated by drawing contour lines and estimating minimum depth on maps published by the Defense Mapping Hydrographic Center, Washington, D.C. In some cases I have remeasured islands included in an earlier study (Heaney 1978) and provide here what I believe are better estimates.

Correlation analysis was conducted using Kendall's tau, a nonparametric statistic, using the Michigan Data Analysis System at the University of Michigan. Multiple regression analyses were done on a Honeywell 66-60 computer using programs in the BMDP series. Simple regression lines were calculated by the least-squares method.

Lists of species that occur on the islands included here are available from the author upon request.

\section{Results}

\section{Analysis of species-richness correlations}

The 14 islands used in the analysis include the three largest islands on the Sunda Shelf and a variety of smaller islands in the South China Sea (Table 1). A linear regression of $\log$ of species number on $\log$ of island area (Fig. 1) accounted for $94 \%$ of the variation. The slope of the regression line $(z=0.235)$ is typical of slopes recorded for a wide

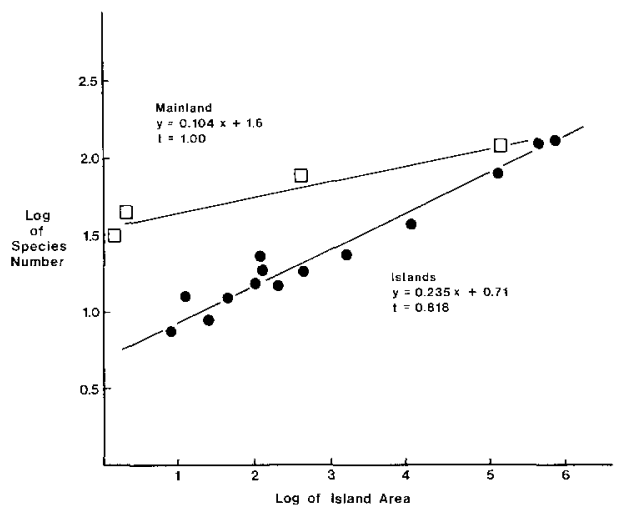

Fig. 1. Relationship between island area and number of non-volant terrestrial mammal species for islands on the Sunda Shelf (solid dots) and for areas on the Malay Peninsula, a "mainland" reference region (open squares). Equations are linear regressions; $t$ is Kendall's tau. The coefficient of determination $\left(r^{2}\right)$ for the islands is 0.939 , and for the Malay Peninsula is 0.945 . Data are from Table 1

variety of organisms on islands (Lomolino 1982; Wright 1981). A correlation analysis of the data in Table 1 showed a significant correlation between species number and both area and elevation, but not with distance to a mainland faunal source, or with depth of intervening water (Table 2). Area and elevation are significantly correlated. A multiple regression of species number on area and elevation accounted for $98 \%$ of the total variation, with the equation taking the form: species number $=6.645$ (log area) +0.023 (elevation) -11.42 . The standardized regression coefficients for $\log$ of area and elevation were 0.741 and 0.267 , respectively.

A similar analysis of area-species richness relationship was carried out for four areas on the Malay Peninsula: the entire area of West Malaysia (Medway 1969), Krau Game Reserve (Medway and Wells 1971), and two sites in lowland forest in Selangor (Harrison 1968). The slope 
Table 2. Correlation matrix for all variables, using Kendall's tau; $*=0.05$ significance level; $* *=0.01$ significance level. Correlation above the diagonal utilize all $\mathbf{1 4}$ islands; those below the diagonal exclude the "source area" islands, i.e., Borneo, Java, and Sumatra. Data from Table 1

\begin{tabular}{llllll}
\hline & Area & Elev. & Dist. & Depth & No. Sp. \\
\hline Area & & $0.69 * *$ & -0.29 & -0.38 & $0.82^{* *}$ \\
Elev. & $0.49 *$ & & -0.29 & -0.38 & $0.82^{* *}$ \\
Dist. & 0.13 & 0.13 & & $0.80^{* *}$ & 0.35 \\
Depth & 0.08 & 0.08 & $0.65^{*}$ & & -0.46 \\
No. Sp. & $0.70^{* *}$ & $0.70^{* *}$ & 0.04 & -0.06 & \\
\hline
\end{tabular}

of the mainland curve $(z=0.104)$ is much less than that for the islands, and provides an estimate of the number of species to be expected in a given area under conditions of unrestricted immigration (Wilcox 1980). The difference between the two lines is likely to be due to extinction on the islands since they were isolated at the end of the Pleistocene (see below).

\section{Rates of colonization}

It is reasonable to assume that the frequency with which terrestrial species of mammals disperse over water is in large part determined by the distance between source areas and islands. The absence of a correlation between species number and distance may indicate either 1) absence of successful colonization, 2) complete success in colonization, i.e., colonization of all suitable habitat on all islands (see Brown 1978, for examples), or 3) that other as yet unidentified factors play significant roles. I assume that non-volant land mammals are not capable of the extremely high rates of dispersal over salt water necessary for "complete success", and so would interpret the absence of a correlation with distance as evidence of no or very low levels of colonization, or of the importance of other unidentified variables.

The rate of colonization in the study area was investigated by testing for a correlation between distance from source areas and species number residuals (the portion of species number on a given island unexplained after multiple correlation with area and elevation), following successful use of this technique by Lomolino (1982). A graph of these variables (Fig. $2 \mathrm{~A}$ ) shows a non-significant relationship, although the slope of the regression line is in the direction expected if colonization occurs. The most appropriate interpretation of these data is that, to the degree of accuracy that current data permit, colonization has been either undetectably low or absent, or that some unknown factor substantially influences colonization.
One of the possible additional variables in determining colonization by rafting or swimming animals are ocean currents, as found by Gill (1976). The prevailing currents on the Sunda Shelf sweep from the north to south between Borneo and the Malay Peninsula, and swing eastward as they pass between Borneo and Java. No apparent relationship exists between location and species residual for the islands under study, so currents do not appear to play a significant role.

In this study, the small amount of variation not explained by area and elevation $(2.3 \%)$ indicates a low rate of colonization. If colonizations were common, then one would expect not only that a correlation with distance would exist, but also that the variation due to distance would be greater than that observed.

\section{Rates of extinction}

The difference between the mainland and island area-species richness curves (Fig. 1) indicates that substantial extinction has taken place on the islands. For example, mainland areas and islands of $100 \mathrm{~km}^{2}$ are estimated to have means of 65 and 15 species respectively, which suggests extinction of $77 \%$ of the original island fauna. The difference in slopes of the lines indicates that the amount of extinction has been least on the largest islands; for example, calculations similar to those above suggest that Borneo has lost 28 species, or $18 \%$.

A second aspect of extinction, i.e., the rate, may be investigated utilizing the differences in depths of water surrounding the various islands. Because time of isolation was determined by the progressive rise of water level during the late Pleistocene, depth of surrounding water should be directly correlated with time since isolation. Estimated isolation times range from 5,000 to $16,000 \mathrm{BP}$, a 9,000 year span. If extinction was constant or random, a correlation should exist between isolation time and species number; if extinction was absent or episodic, or was strongly skewed temporally, no correlation should exist. A multiple regression analysis was used to remove the effects of island area and elevation from species number, as described above. Depth of water surrounding each island was used to estimate time since isolation; this assumes that there has been little change in relative elevation of different parts of the sea floor (see Methods).

The results shown in Fig. 2B indicate no significant correlation, and a slope not significantly different from zero. Thus, extinction during the 9,000 years was either undetectably low, episodic, or skewed temporally. The first of these three alternatives is falsified by the data presented above. One might infer that the generally documented stability of
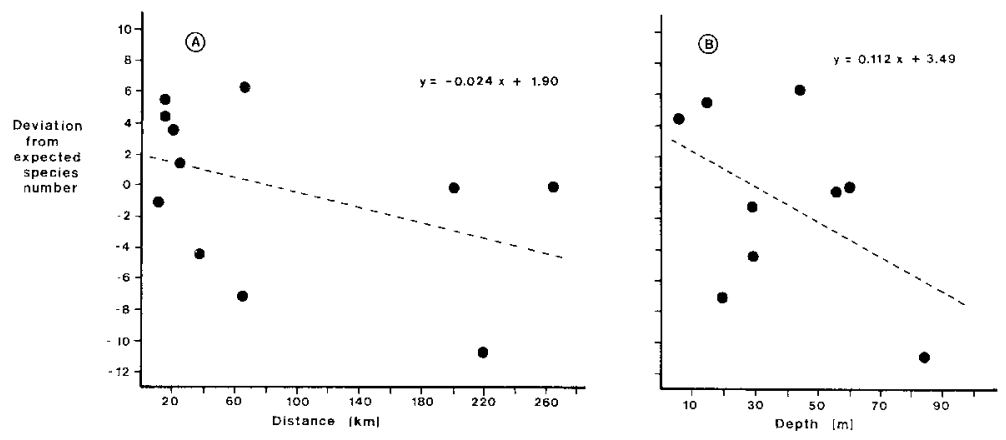

Fig. 2A, B. Graphs of species-area residuals (see text for explanation) vs. A distance from the nearest source area and $\mathbf{B}$ minimum depth of water to a source area. Neither regression line is statistically significant 
Table 3. Composition of faunas of Sunda Shelf islands, broken down by order or major group. Correlation and regression analyses did not include data from the Malay Peninsula; these are included for reference only. The slope and $y$-intercept of the regression with log of island area is given for each group, along with a non-parametric correlation value (Kendall's tau)

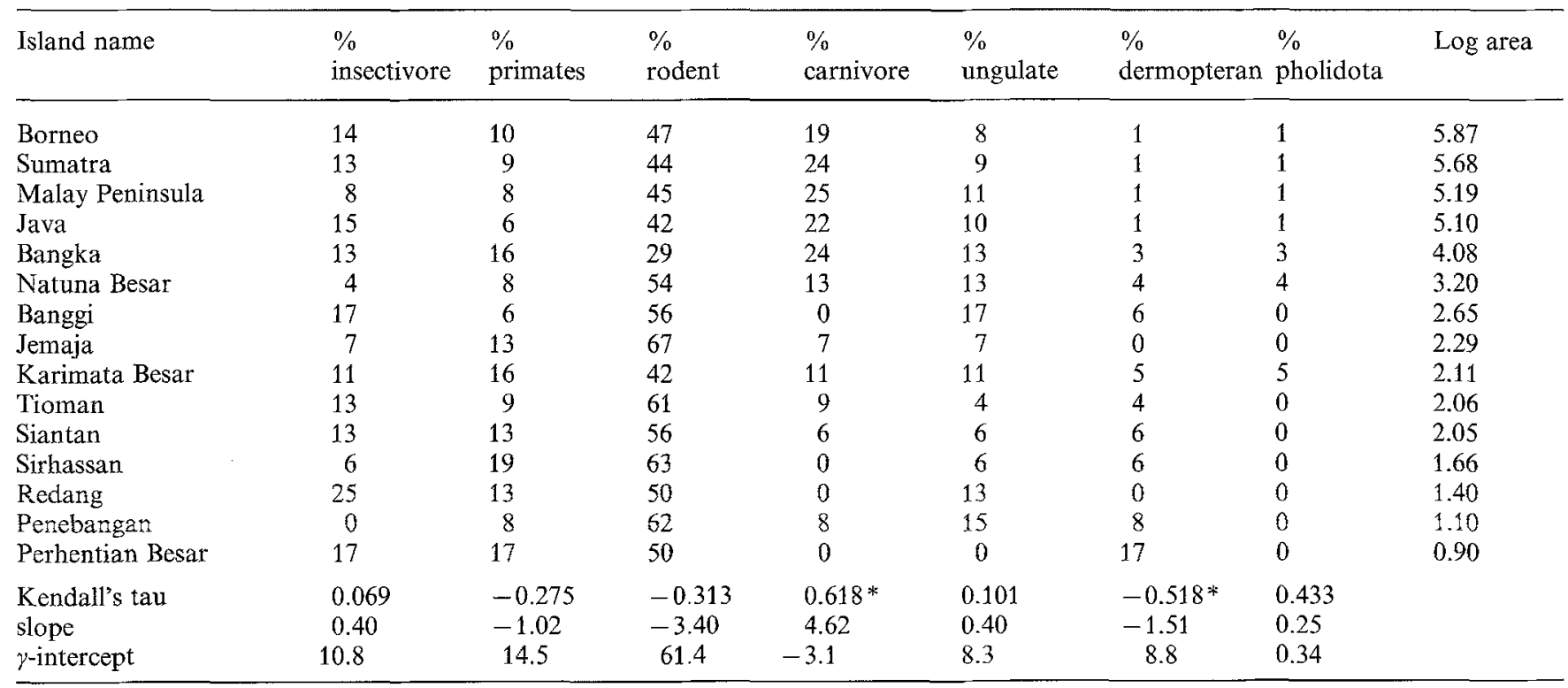

$*=\beta<0.05 ; * *=\beta<0.01$

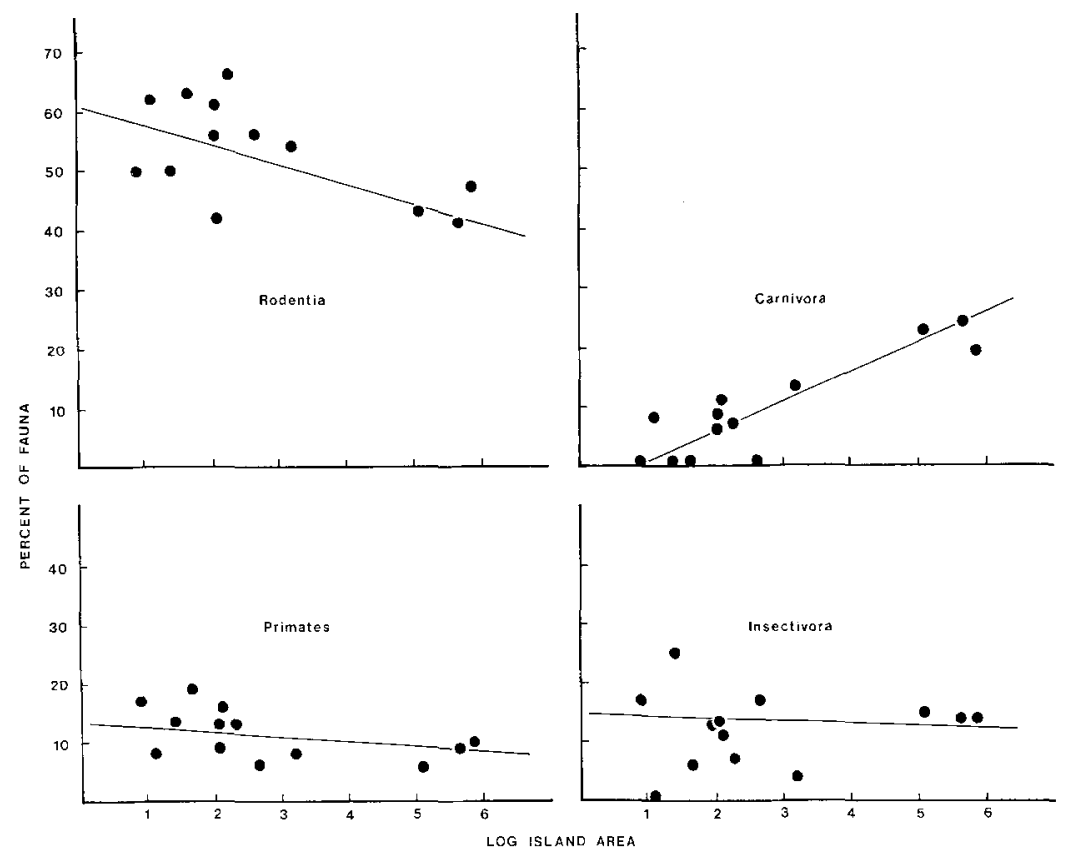

Fig. 3. Relationship between island area and percentage of the fauna falling into the four most specious groups. Data, regression line coefficients, and correlation coefficients are given in Table 3 . Only carnivores have a slope that differs significantly from zero (see text)

climate and ocean water level in post-Pleistocene Southeast Asia (Verstappen 1975) would not induce episodic extinction, and island biogeographical theory (discussed below) points toward rapid extinction immediately following isolation. However, such inference is rather weak, and should be investigated further.

\section{Composition of the island faunas}

The above discussion has dealt with the land mammal fauna as a single unit. One might ask, what changes took place in the composition of the faunas as the islands decreased in size? This is addressed here by calculating the percentage of the fauna included in seven major taxonomic groups:
Insectivora (including tree shrews), Primates, Rodentia, Carnivora, and "Ungulata" (including Artiodactyla, Perissodactyla, and Proboscidea), Dermoptera, and Pholidota. This is a coarse-grained approach, but should be sufficient to discern major changes in average faunal composition. These data are summarized in Table 3 , and most data are graphed in Fig. 3.

Two generalizations may be drawn from Fig. 3. First, a strong relationship is apparent between islands area and percent of rodents, carnivores, primates, and insectivores in the island faunas. Second, it appears that the scatter of points (i.e., the variation in proportion) for a given group of mammals is larger for small islands than for large islands. This may be a statistical artifact of increasing the contribu- 
tion of each single species to the total percentage. For example, the single species of dermopteran, the flying lemur, accounts for about $1 \%$ of the fauna on Borneo, but up to $17 \%$ on the smallest island, Perhentian Besar (Table 3 ). Viewed with this variation in mind, the regression lines indicate consistent patterns in average makeup of the faunas. Rodent species comprise the bulk of the faunas, and show a marked increase in percentage with decreasing island area (not a significant correlation using Kendall's tau, but significant at $P<0.05$ in a parametric analysis; $r=-0.55$ ). Insectivore, primate, and ungulate species make up small but fairly consistent proportions of the faunas. These show slight increases on the smaller islands, but the slopes of the regression lines do not differ significantly from zero (Table 3). Carnivore species exhibit a pattern much different from the others; they are the only group to constitute a significantly decreasing proportion of the fauna as island area decreases, and are absent from small islands. Of five islands under $100 \mathrm{~km}^{2}$, only one has any mammalian carnivore present.

\section{Discussion}

The conditions under which the contemporary islands on the Sunda Shelf gained their faunas probably were different from those existing today. Temperatures during the late Pleistocene may have been as much as $4^{\circ}$ to $5^{\circ} \mathrm{C}$ cooler, and rainfall was more seasonal and somewhat reduced, causing the development of mixed forest-savannah vegetation in some areas (Hooijer 1975; Medway 1972, 1977b; Muller 1972, 1975; Verstappen 1975). Large species such as the giant pangolin (Manis paleojavanica), tiger (Panthera tigris), Malayan tapir (Tapirus indicus), Sumatran thinoceros (Didermoceros sumatrensis), and Indian elephant (Elephas maximus) once ranged widely across the Sunda Shelf, but subsequently have become greatly reduced in range, or extinct (Hoojier 1975; Medway 1972, 1977b). Little is known about the late Pleistocene distribution of small mammals because of a lack of fossil evidence, but the large number of species shared by the four largest islands (Davis 1962) suggests that dispersal took place freely. Even montane species such as the lesser gymnure (Hylomys suillus), Himalayan water shrew (Chimarrogale himalayica), and ferret-badger (Melogale orientalis) traversed the lowland areas between major mountain masses during the Pleistocene and currently are widespread in appropriate habitats on the large (and a few small) islands.

MacArthur (1972:100) suggested that "supersaturated" islands such as these on the Sunda Shelf should exhibit highest extinction rates soon after isolation, and progressively lower rates as the fauna is depleted. Data from lizards on islands off of Baja California support this prediction (Wilcox 1978). Additionally, large islands are predicted to have lower extinction rates than smaller islands. In a recent review of the equilibrium model of island biogeography, Brown (1978) concluded that island area is the most important variable determining species richness. He also suggested that vagility of birds is so high that extinction is sometimes effectively zero, even under circumstances involving substantial distances, thus supporting similar conclusions by Lack (1976). However, Brown assumed that extinction plays a continuing role in limiting richness of animals having low dispersal powers, particularly terrestrial mammals (see also Diamond 1976). Although there is little question that extinction took place in the habitat islands he studied sometime after their isolation, he presented no evidence regarding present rates of extinction.

The data summarized above indicate that massive extinction took place on the Sunda Shelf as ocean level rose during latest Pleistocene and early Recent times. The available evidence supports the temporally-skewed extinction curve hypothesized by MacArthur (1972:100); it does not support the occurrence of continuing extinction, but neither does it adequately falsify it.

The data on faunal composition suggest that, although a tremendous change in number of species has occurred on the Sunda Shelf islands, there is a surprising degree of consistency in the proportionate faunal composition. Only the carnivores change dramatically; they decrease in number and proportion as island area decreases, and usually are absent on islands with fewer than 15 species of terrestrial mammals. Such consistency in faunal composition of insular communities apparently has not been noted previously for mammals, but has been documented for insular birds (e.g., Terborgh et al. 1978).

Terborgh and Winter (1980) listed three major factors that contribute to determining the probability of extinction of individual species on land-bridge islands: trophic level, body size, and initial rarity. The disappearance of carnivores from the small Sunda Shelf islands could indicate the importance of trophic level or of body size, since most carnivores are large. Using the size of the species on the Malay Peninsula (Medway 1969) as the standard for comparison, I found no clear tendency for size to influence extinction among insectivores, primates, and sciurid and murid rodents. Among carnivores, the largest species show high extinction probabilities on medium and small islands: tigers, leopards, bears, badgers, otters, and wild dogs are nearly always absent on any but the largest islands, whereas the smaller (and more omnivorous) viverrids show relatively lower extinction probabilities. Ungulates show a similar pattern: elephants, wild cattle, rhinoceros, and tapirs are absent from any but the three largest islands, whereas the medium sized Malayan sambar and bearded pig are more widespread, and the small mouse-deer are abundantly represented on small islands. Thus, body size is correlated with the probability of extinction at the upper end of the size scale, but may not be at the lower end of the scale.

The third factor listed by Terborgh and Winter, initial rarity, was discussed with reference to a study of a series of isolated forest reserves in southern Brazil by Willis (1979). Willis found that virtually all of the species persisting in the smallest forest reserve are also present in the next larger one; this pattern continued through to the largest reserve. Willis further demonstrated that rarity was the best predictor of extinction; only the most abundant species in the largest reserve were present in the next smaller reserve, and so on to the smallest reserve. Medway (1966) provided less quantitative but strikingly similar results in a study of three neighboring islands off the east coast of the Malay Peninsula. All of the species found on the smallest island, Pemanggil, are present on the medium sized island, Aor, and so on in "nested" fashion to the Malay Peninsula. All of the species found on Aor were noted as being common or abundant on the largest island, Tioman, and nearly all of those on Tioman are among the most common small mammals on the Malay Peninsula. Medway also noted that nearly all of the species on Tioman are 
morphologically distinct from their mainland conspecifics, i.e., have undergone noticable evolution since isolation, and that small mammal abundance on Tioman was three to five times higher than in comparable habitat on the peninsula.

Recent studies of island biogeography have relied heavily on the equilibrium model proposed by MacArthur and Wilson (1963, 1967; see also Brown and Kodric-Brown 1977) as a framework in which to conduct investigations. The primary assumption of the model is that species richness patterns are determined by the interaction of extinction and immigration of new species. Most studies have dealt with systems that exhibit relatively high immigration rates, and these have generally conformed to the predictions of the model (e.g., Lomolino 1982; Patrick 1967; Simberloff and Wilson 1970; Simberloff 1974), although some criticisms of the simplicity of the model have been expressed (Abbott and Grant 1976; Johnson 1975; Lynch and Johnson 1974; Rusterholz and Howe 1979; Schoener 1976). Fewer studies have dealt with the other end of the continuum, i.e., systems in which colonization rates are very low (Brown 1971, 1978; Patterson 1980; Wilcox 1978). MacArthur and Wilson (1967:145-180) suggested that selection should operate under these conditions to gradually reduce the extinction rate of residents by favoring "K-selection" strategies. For species with long life-spans, extinction should occur at very low rates; a fauna made up of such species might be expected to persist indefinitely (pp 73-77). Moreover, if species abundance is low enough and island size large enough, adaptive radiation is likely to occur (pp 173-178), further offsetting the effects of extinction on species number.

Wilcox (1978) examined a set of faunas that seem to support MacArthur and Wilson's predictions regarding persistence of island faunas. He found that lizard faunas on post-Pleistocene land-bridge islands off the coast of Baja California receive almost no immigrants, and the "relaxation" from super-saturated faunas has proceeded gradually. Although he worked with no islands isolated longer ago than ca. 12,000 BP, his data (see his Fig. 1) suggest that net extinction should approach zero on islands isolated for about 20,000 years, and should leave about $25 \%$ of the species diversity that is found on comparable sites on the adjacent mainland. Brown (1971, 1978) and Patterson (1980) described mammalian faunas in habitat islands in the southwestern United States that have received little or no colonization since the end of the Pleistocene, but are far from the brink of total extinction. These studies leave open the questions of whether the faunas may persist indefinitely, as predicted by MacArthur and Wilson, and of the possible influence of speciation in determining species richness in isolated faunas.

The results of this study suggest that the rate of colonization has been low since the archipelago was formed at the end of the Pleistocene. Major extinction has taken place since isolation of the islands, and most extinction may have occurred during the first few thousand years. Extinction has not caused extirpation of entire faunas, even on islands of only eight $\mathrm{km}^{2}$.

These conclusions, together with the following three observations, suggest that the mammalian faunas under study may represent a system approaching a stable state, such as the one envisioned by MacArthur and Wilson (1967:173-178), in which colonization is low, but the fauna persists indefinitely. First, islands in moderately deep water (i.e., less than $180 \mathrm{~m}$ and more than $120 \mathrm{~m}$ ), such as the Mentawi chain, located southwest of Sumatra (Chasen and Kloss 1927; Heaney, unpub. data; Wilcox 1980), have rich and diverse faunas, even though, on the basis of surrounding water depth, they probably have been isolated since the mid-Pleistocene, perhaps 150,000 years of isolation. Second, the islands under study here have maintained species in all major niches (with the exception of carnivores on small islands), and so appear to be balanced communities (MacArthur and Wilson 1967:177). Third, major changes in body size in many species (Medway 1966; Heaney 1978, and unpub. data) indicate that adaptations related to island carrying capacity and life history strategies, such as those discussed by MacArthur and Wilson (1967:73-77), have occurred. If such stable systems do exist, further studies might be expected to add a new dimension to future research on island faunas, since terrestrial mammals are not alone in their low dispersal ability. It is conceivable, and indeed has been argued in specific cases (e.g., Lack 1976), that speciation among some insular organisms may exceed the rate of colonization, thus replacing it as the principal source of new species in a given fauna. If speciation is high for low-vagility insular species, then the probability of existence of stable systems seems high.

The following assertions and predictions are presented here as testable hypotheses that should be investigated to gain the necessary empirical evidence to establish a more comprehensive understanding of mammalian island biogeography. They are phrased in the context of Southeast Asian mammals, but might be adapted to other regions and organisms. The first four are empirically based on evidence presented above, and the next two are derived from these.

1) Island area is the major factor limiting species richness of terrestrial mammalian faunas on land-bridge islands, presumably within any given climatic region. A strong correlation of species richness with elevation indicates that habitat diversity may also be important.

2. Extinction produces balanced faunas on all land-bridge islands regardless of size, with the exception of carnivores and large ungulates.

3) The rate of colonization over salt-water gaps by terrestrial non-volant mammals is extremely low.

4) Following a period of a high rate of extinction subsequent to isolation from a mainland, the rate of extinction among land mammals is very low.

5) Old oceanic islands that are near faunal source areas should have numbers of terrestrial mammals equal to old landbridge islands of the same size. If colonization rate is greater than zero, then this hypothesis necessarily follows from 1 , above, given enough time.

6) Oceanic islands should have faunas of different composition than land-bridge islands, since they are derived from those species that colonize best over water, not equally from all source species. This hypothesis follows from 2 and 3 .

Ideal places to test these predictions are the other archipelagos of Southeast Asia, especially the Philippines, and islands on and near the Arafura Shelf that connects Australia and New Guinea. Smaller, more diverse organisms on the smaller islands that lie off the coasts of other continental areas might also be investigated profitably.

Acknowledgments. The manuscript has benefitted from comments by M.A. Bogan, G.E. Glass, P.R. Grant, R.S. Hoffmann, J.H. 
Honacki, T.J. McIntyre, N.A. Muckenhirn, G.G. Musser, P. Myers, B.D. Patterson, V.L. Roth, R.W. Thorington, R.M. Timm, and D.R. Wells. Partial support was provided by the Smithsonian Institution, Office of Academic Affairs. Musser and Thorington provided access to specimens under their care, and S.F. Campbell, G. Lake, and P. Myers assisted with preparation of the manuscript.

\section{References}

Abbott I, Grant PR (1976) Nonequilibrial bird faunas on islands. Am Natur 110:507-528

Bartlett AS, Barghoorn ES (1973) Phytogeographic history of the isthmus of Panama during the past 12,000 years (a history of vegetation, climate, and sea-level change). In: Graham A (ed) Vegetation and vegetational history of northern Latin America

Brown JH (1971) Mammals on mountaintops: nonequilibrium insular biogeography. Am Natur 105:467-478

Brown JH (1978) The theory of insular biogeography and the distribution of boreal birds and mammals. Great Basin Nat Mem 2:209-227

Brown JH, Kodric-Brown A (1977) Turnover rates in insular biogeography: effect of immigration on extinction. Ecology 58:445-449

Chasen FN (1935) On a collection of mammals from the Natuna Islands, South China Sea. Bull Raffles Mus 10:5-42

Chasen FN (1940) A handlist of Malaysian mammals: a systematic list of the mammals of the Malay Peninsula, Sumatra, Borneo and Java, including adjacent small islands. Bull Raffles Mus 15: $\mathrm{xx}+1-209$

Chasen FN, Kloss CB (1927) Spolia Mentawiensia - Mammals. Proc Zool Soc London 53:796-840

Davis DD (1962) Mammals of the lowland rain-forest of North Borneo. Bull Nat Mus Singapore 31:1-129

Diamond JM (1976) Relaxation and differential extinction on landbridge islands: applications to natural preserves. In: Frith HJ, Calaby JH (eds) Proc 16th Int Ornith Cong, Canberra. Australia Acad Sci, pp 616-628

Dunn FL, Dunn DF (1977) Maritime adaptations and exploitation of marine resources in Sundaic Southeast Asian prehistory. Modern Quaternary Res Southeast Asia 3:1-28

Gill A (1976) Genetic divergence of insular populations of deer mice. Biochem Genet 14:835-848

Hamilton W (1979) Tectonics of the Indonesian region. Geol Surv Professional Pap 1078: $1 x+1-345$

Harrison JL (1968) The effect of forest clearance on small mammals. In: Talbot LM, Talbot MH (eds) Proc Conference on Conservation of Nature and Natural Resources in Tropical Southeast Asia. IUCN Publ. (new ser.) 10:153-158

Heaney LR (1978) Island area and body size of insular mammals: evidence from the tri-colored squirrel (Callosciurus prevosti) of Southeast Asia. Evolution 32:9-17

Hooijer DA (1975) Quaternary mammals west and east of Wallace's Line. Netherlands J Zoology 25:46-56

Johnson NK (1975) Controls of number of bird species on montane islands in the Great Basin. Evolution 29:545-567

Lack D (1976) Island Biology. Univ California Press, Berkeley

Lomolino MV (1982) Species-area and species-distance relationships of terrestrial mammals in the Thousand Island region. Oecologia (Berlin) 54:72-75

Lynch JF, Johnson NK (1974) Turnover and equilibria in insular avifaunas, with special reference to the California Channel Islands. Condor 76:370-384

Lyon MW (1906) Mammals of Banka, Mendanau, and Billiton Islands, between Sumatra and Borneo. Proc US Nat Mus 31:575-612

MacArthur RH (1972) Geographical ecology; patterns in the distribution of species. Harper and Row, NY

MacArthur RH, Wilson EO (1963) An equilibrium theory of insular zoogeography. Evolution 17:373-387

MacArthur RH, Wilson EO (1967) The theory of island biogeography. Princeton Univ Press, NJ Monogr Pop Biol 1:1-203
Medway L (1966) The Mammals. In: Observations on the fauna of Pulau Tioman and Pulau Tulai. Bull Nat Mus Singapore 34:9-32

Medway L (1969) The wild mammals of Malaya and offshore islands including Singapore. Oxford Univ Press, London

Medway L (1972) The Quaternary mammals of Malesia; a review. In: Ashton P, Ashton M (eds) The Quaternary Era in Malesia. Dept Geog Univ Hull Misc Series 13:1-122

Medway L (1977) The mammals of Borneo (2nd ed). Malayan Branch Royal Asiatic Soc, Singapore

Medway L (1977b) The Niah excavations and an assessment of the impact of early man on mammals in Borneo. Asian Perspectives 20:51-69

Medway L, Wells DR (1971) Diversity and density of birds and mammals at Kuala Lompat, Pahang. Malay Nat J 24:238-247

Muller J (1972) Palynological evidence for change in geomorphology, climate, and vegetation in the Mio-Pliocene of Malesia. In: Ashton P, Ashton M (eds) The Quaternary Era in Malesia. Dept Geog Univ Hull Misc Series 13:1-122

Muller J (1975) Pollen analytical studies of peat and coal from northwest Borneo. Modern Quaternary Res Southeast Asia $1: 83-86$

Musser GG (1981) A new genus of arboreal rat from West Java, Indonesia. Zool Verhand (Leiden) 189:1-35

Patrick R (1967) The effect of invasion rate, species pool, and size of area on the structure of the diatom community. Proc Natl Acad Sci (USA) 58:1335-1342

Patterson BD (1980) Montane mammalian biogeography in New Mexico. Southwestern Natur 25:33-40

Robinson HS, Kloss CB (1918) Results of an expedition to Korinchi Peak, Sumatra. I Mammals. J Federated Malay States Mus $8: 1-80$

Rusterholz KA, Howe RW (1979) Species-area relations of birds on small islands in a Minnesota lake. Evolution 33:468 477

Schoener TW (1976) The species-area relation within archipelagos: models and evidence from island land birds. In: Frith JJ, Calaby JH (eds) Proc 16th Intl Ornith Cong, Canberra. Australia Acad Sci, pp 629-642

Simberloff DS (1974) Equilibrium theory of island biogeography and ecology. Ann Rev Ecol Syst 5:161-182

Simberloff DS, Wilson EO (1970) Experimental zoogeography of islands. A two-year record of colonization. Ecology 51:934-937

Terborgh J, Winter B (1980) Some causes of extinction. In: Soule $\mathrm{ME}$, Wilcox BA (eds) Conservation biology: an evolutionaryecological perspective. Sinauer Associates, Sunderland Massachusetts, pp 119-133

Terborgh J, Faaborg J, Brockman HJ (1978) Island colonization by Lesser Antillean birds. Auk 95:59-72

Verstappen HT (1975) On paleoclimates and landform development in Malesia. Modern Quaternary Res Southeast Asia $1: 3-35$

Wilcox BA (1978) Supersaturated island faunas: a species-age relationship for lizards on post-Pleistocene land-bridge islands. Science 199:996-998

Wilcox BA (1980) Insular ecology and conservation. In: Soule ME, Wilcox BA (eds) Conservation biology : an evolutionary-ecological perspective. Sinauer Associates, Sunderland Massachusetts, pp $95-117$

Wilks PJ (1979) Mid-Holocene sea level and sedimentation interactions in the Dovey estuary area, Wales. Paleogeog, Paleoclimat, Paleoecol 26:17-36

Wright SJ (1981) Intra-archipelago vertebrate distributions: the slope of the species-area relation. Am Natur 118:726-748

Willis EO (1979) The composition of avian communities in remanescent woodlots in southern Brazil. Pap Avulsos Zool Mus S Paulo 33:1-25

Received May 6, 1983 